\title{
ADVERSE DRUG REACTION REPORTING BY DOCTORS IN A DE- VELOPING COUNTRY: A CASE STUDY FROM GHANA
}

\author{
G.T. SABBLAH ${ }^{1}$, P. AKWEONGO ${ }^{2}$, D. DARKO ${ }^{1}$, A. N. O. DODOO ${ }^{3}$, A. M. SULLEY ${ }^{3}$ \\ ${ }^{1}$ Ghana Food and Drugs Authority, P.O. Box CT 2783 Cantonments, Accra, Ghana, ${ }^{2}$ Department of \\ Epidemiology, School of Public Health, University of Ghana, Legon, Accra, Ghana, ${ }^{3}$ Centre for Tropical \\ Clinical Pharmacology \& Therapeutics, University of Ghana Medical School, P.O. Box GP 4236, Accra, \\ Ghana
}

DOI: $h t t p: / / d x . d o i . o r g / 10.4314 / g m j . v 48 i 4.4$

Corresponding Author: Mr. George Tsey Sabblah

Email: gyorg1@yahoo.co.uk

Conflict of Interest: None declared

\section{SUMMARY}

Background: Spontaneous adverse drug reaction reporting is the most widely used and cost effective method of monitoring the safety of drugs. This method is heavily afflicted by underreporting by healthcare professionals. The study aims at assessing adverse drug reaction (ADR) reporting rate by doctors, knowledge of the reporting system and attitudes to SADR in the Greater Accra region.

Methods: This was a cross sectional survey of 259 doctors randomly selected from 23 hospitals classified as government 199 (76.8\%), quasi-governmental $43(16.6 \%)$ and private $17(6.6 \%)$ hospitals in the Greater Accra Region of Ghana. Data collection was by self-administered questionnaire from May 5, 2012July 6, 2012. Descriptive statistics was used to describe the background characteristics of the doctors and the outcome measures like training and reasons for ADR reporting were summarized as frequencies and percentages.

Results: One-third (27.4\%) of doctors surveyed had received previous training on drug safety monitoring and ADR reporting; training and knowledge of the reporting system was found to improve reporting. More than half $154(59.5 \%)$ of the doctors had seen a patient with suspected ADR in the past one year although only $31(20 \%)$ had reported it by completing the SADR reporting form. Doctors working in government hospitals were about 5 times more likely to report than those in private hospitals $[\mathrm{OR}=4.94,95 \% \mathrm{CI}(1.55-15.69)]$.

Conclusion: Training and knowledge of the ADR reporting system were found to be associated with the likelihood of reporting an ADR. Most of the doctors had not previously received training on ADR reporting.

Keywords: Spontaneous reporting, adverse drug reaction, underreporting, doctors, Ghana

\section{INTRODUCTION}

During drug development, only a limited number of people, with carefully selected characteristics are monitored for the safety and efficacy of the drug, hence it is the common adverse drug reactions (ADRs) following proper use of the medication that get detected. Spontaneous Reporting (SADR) is the most widely employed method for monitoring entire populations for the safety of drugs in real-life use. ${ }^{1,2}$ Compared to other methods, SADR is very cheap to implement and with this system, all medicines can be monitored in a population on an ongoing basis, with both patient- and populationlevel analyses done.

Despite these benefits, the voluntary nature of SADR makes it heavily affected by poor reporting by patients and/or healthcare professionals. Ghana began its spontaneous reaction reporting programme in June 2001, and joined the WHO Programme for International Drug Monitoring the same year as the $65^{\text {th }}$ member, yet the reporting rate of about 6 reports per $1,000,000$ population per year is woefully below the WHO recommended reporting rate of 200 per million per year. ${ }^{3,4}$

Annual reporting rates of between 300-500 reports per $1,000,000$ population had been reported in Australia, Denmark, France, Ireland, Sweden and UK., ${ }^{5,6}$ Although reporting rates of adverse drug reactions by healthcare professionals had not been studied in Ghana, studies in Nigeria had reporting rates of between $2 \%$ to $32 \%$. This is less than reporting rates of $47 \%$ to $77 \%$ identified by Belton, et al. 1997 in some European countries with well-established spontaneous reporting systems. ${ }^{5}$ The factors contributing to low reporting of ADRs by health professionals have been summarized as the 'seven deadly sins' by Inman in 1996 as complacency, insecurity and legal issues, case series publication, diffidence, professional responsibility, lethargy and financial incentives to report. ${ }^{10,11}$ 
Unawareness of the reporting form and ignorance of the reporting procedure were also found to be associated with underreporting. ${ }^{9}$ Training had been found as the best intervention to improve SADR reporting by healthcare professionals. ${ }^{12,13}$ Since doctors are the most qualified by training to make diagnosis of ADRs and very likely to see patients with ADRs in the largely urban region of Greater Accra, their contribution to spontaneous reporting cannot be underestimated. However doctors' reports constitute only about $12 \%$ of the ADR reports collected in Ghana. There is also limited knowledge about the factors that may contribute to their low reporting of adverse drug reactions, and understanding this will be helpful in improving the reporting rate.

The main objective of this study is to assess adverse drug reaction reporting rate by doctors, knowledge of the reporting system and attitudes to spontaneous adverse drug reaction reporting in the Greater Accra region of Ghana.

\section{METHODS}

\section{Study Design and Location:}

The study was a cross sectional survey of doctors involved in clinical practice in hospitals in the Greater Accra Region of Ghana. The Greater Accra Region was chosen because 38\% (920) of the 2,421 doctors registered by the Ghana Dental and Medical Council practice in the region. ${ }^{14}$ The population of the Greater Accra region is 4,010,054 with a doctor to patient ratio of one doctor to 9,939 patients. ${ }^{15,16}$

\section{Sampling:}

Doctors who were involved in clinical practice at the time of the study and had practiced for at least one year were included, whilst those who had not been involved in clinical practice in the past one year were excluded from the study. The study questionnaire was administered to 300 doctors involved in clinical practice selected by random sampling (representing $11 \%$ of doctors in Ghana) ${ }^{14}$ from 26 hospitals in the Greater Accra region. Out of this, $259(86.3 \%)$ of the questionnaires were retrieved, which gave $13.7 \%$ non-response rate. The hospitals consisted of 13 government hospitals, 4 quasi-government and 6 private hospitals.

\section{Data Collection and Quality Control:}

Data collection was from May 5, 2012 to July 6, 2012. A semi-structured self-administered anonymous questionnaire was distributed to the doctors. The survey questionnaire was pretested to determine its appropriateness and suitability for the study. Research assistants involved in the study were trained on how to present the study objectives and overview of the questionnaire to the doctors. To improve the response rate, the doctors were requested to complete the questionnaires in the presence of the investigator or research assistants. However, doctors who preferred to complete the questionnaires later were given a maximum of two working days after which they were revisited for collection. Three re-visits were allowed and if the doctor did not complete the questionnaire, it was retrieved. In situations where retrieval was unsuccessful, this was assumed to be a non-response.

The main outcome measures were whether or not respondents had received training in ADR reporting, and the proportion of respondents who had reported ADRs after seeing them. Information obtained using the questionnaire included background information about respondents and their working environments such as age, gender, professional rank, average number of patients seen per day, and type of facility (government, quasigovernment or private).

The questionnaire also obtained information about whether or not respondents had ever received training in ADR reporting, whether or not they had seen patients with ADRs and if they reported those ADRs. For those who did not report, reasons for not reporting were solicited. Level of knowledge of the ADR reporting system was assessed through self-scoring by respondents. Respondents were also asked if it was their professional duty to report ADRs, and suggestions on how to improve reporting system were also solicited.

\section{Data Processing and Statistical Analysis:}

Data collected were entered into STATA Version 10. Descriptive statistics (frequency tables) was used to describe the background characteristics of the doctors. The doctors were grouped into three categories, namely house officers, medical officers (consisting of medical officers, senior medical officers and principal medical officers) and specialists (consisting of specialists and consultants). The data (categorical variables) were summarized as frequencies and percentages.

Cross tabulation was used in comparing ADR reporting between groups such as males versus females; and different age groups, professional ranks, levels of knowledge of the ADR reporting system and type of health facility. Chi square tests were performed to test for association between the categorical variables above and reporting of ADRs. Logistic regression was used to further explore associations between the categorical variables above and ADR reporting and presented as odd ratios and corresponding $95 \%$ confidence intervals.

A p-value $\leq 0.05$ was considered statistically significant. Analysis was done using STATA Version 10 (StataCorp, 4905 Lakeway Drive, TX). Histograms 
were obtained using Microsoft Excel (Microsoft Inc., 2007).

\section{Ethical Considerations:}

Ethical approval was sought from the Ghana Health Service Ethical Review Committee of the Research and Development Division of the Ghana Health Services for the conduct of the study. Identities of doctors who provided their names on questionnaires were kept confidential. There was minimal or no risk associated with participation in this study and no compensation was paid to the participants.

\section{RESULTS}

The response rate was $86.3 \%$. Characteristics of doctors who participated in this study are presented in $\mathrm{Ta}-$ ble 1 . Level of training of doctors on drug safety monitoring and ADR reporting is presented in Table 2. Only $27.4 \%$ of doctors had received training on drug safety monitoring and ADR reporting.

Table 1 Background characteristics of doctors participating in ADR reporting

\begin{tabular}{|c|c|c|c|}
\hline \multicolumn{2}{|c|}{ Background Characteristics } & \multirow{2}{*}{$\begin{array}{l}\begin{array}{l}\text { Frequency } \\
\text { (N=259) }\end{array} \\
53\end{array}$} & \multirow{2}{*}{\begin{tabular}{|l} 
Percen \\
20.5
\end{tabular}} \\
\hline Age (years) & $\leq 29$ & & \\
\hline & $30-34$ & 86 & 33.2 \\
\hline & $35-39$ & 58 & 22.4 \\
\hline & $40-44$ & 28 & 10.8 \\
\hline & $45-49$ & 13 & 5.0 \\
\hline & $50-54$ & 11 & 4.3 \\
\hline & $\geq 55$ & 10 & 3.9 \\
\hline \multirow[t]{2}{*}{ Gender } & Male & 166 & 64.1 \\
\hline & Female & 93 & 35.9 \\
\hline \multirow[t]{3}{*}{ Rank } & House Officer & 51 & 19.7 \\
\hline & Medical Officer & 136 & 52.5 \\
\hline & Specialist & 72 & 27.8 \\
\hline \multirow[t]{3}{*}{ Level of Facility } & $\begin{array}{l}\text { Teaching Hospi- } \\
\text { tal }\end{array}$ & 130 & 50.2 \\
\hline & $\begin{array}{l}\text { Regional Hospi- } \\
\text { tal }\end{array}$ & 54 & 20.9 \\
\hline & District Hospital & 75 & 28.7 \\
\hline \multirow{5}{*}{$\begin{array}{l}\text { Patients seen per } \\
\text { day }(\mathrm{N}=256)\end{array}$} & $\leq 14$ & 23 & 9.0 \\
\hline & $15-24$ & 57 & 22.3 \\
\hline & $25-34$ & 77 & 30.1 \\
\hline & $35-44$ & 51 & 19.9 \\
\hline & $\geq 45$ & 48 & 18.8 \\
\hline \multirow{2}{*}{$\begin{array}{l}\text { Number of years } \\
\text { practiced }\end{array}$} & $\leq 8$ & 170 & 65.6 \\
\hline & $\geq 9$ & 89 & 34.4 \\
\hline \multirow{3}{*}{ Place of Work } & Government & 199 & 76.8 \\
\hline & $\begin{array}{l}\text { Quasi- } \\
\text { government }\end{array}$ & 43 & 16.6 \\
\hline & Private & 17 & 6.6 \\
\hline
\end{tabular}

One hundred and fifty-four $154(59.5 \%)$ of the respondents had seen a patient with suspected adverse drug reaction in the past one year although only 31
(20\%) of them had reported it by completing the spontaneous adverse drug reaction reporting form.

Table 2 Level of training on drug safety monitoring and ADR reporting

\begin{tabular}{|l|l|l|l|}
\hline Type of facility & $\begin{array}{l}\text { Total no. of } \\
\text { respondents }\end{array}$ & $\begin{array}{l}\text { No. of doc- } \\
\text { tors trained }\end{array}$ & Percent \\
\hline Government & 199 & 52 & 26.1 \\
\hline $\begin{array}{l}\text { Quasi- } \\
\text { government }\end{array}$ & 43 & 17 & 39.5 \\
\hline Private & 17 & 2 & 11.8 \\
\hline
\end{tabular}

The most prominent reasons given by the doctors for not reporting were unavailability of the reporting form (43.1\%) and lack of knowledge of the reporting procedures $(28.5 \%)$. Figure 1 presents reasons given by doctors for not reporting ADRs.

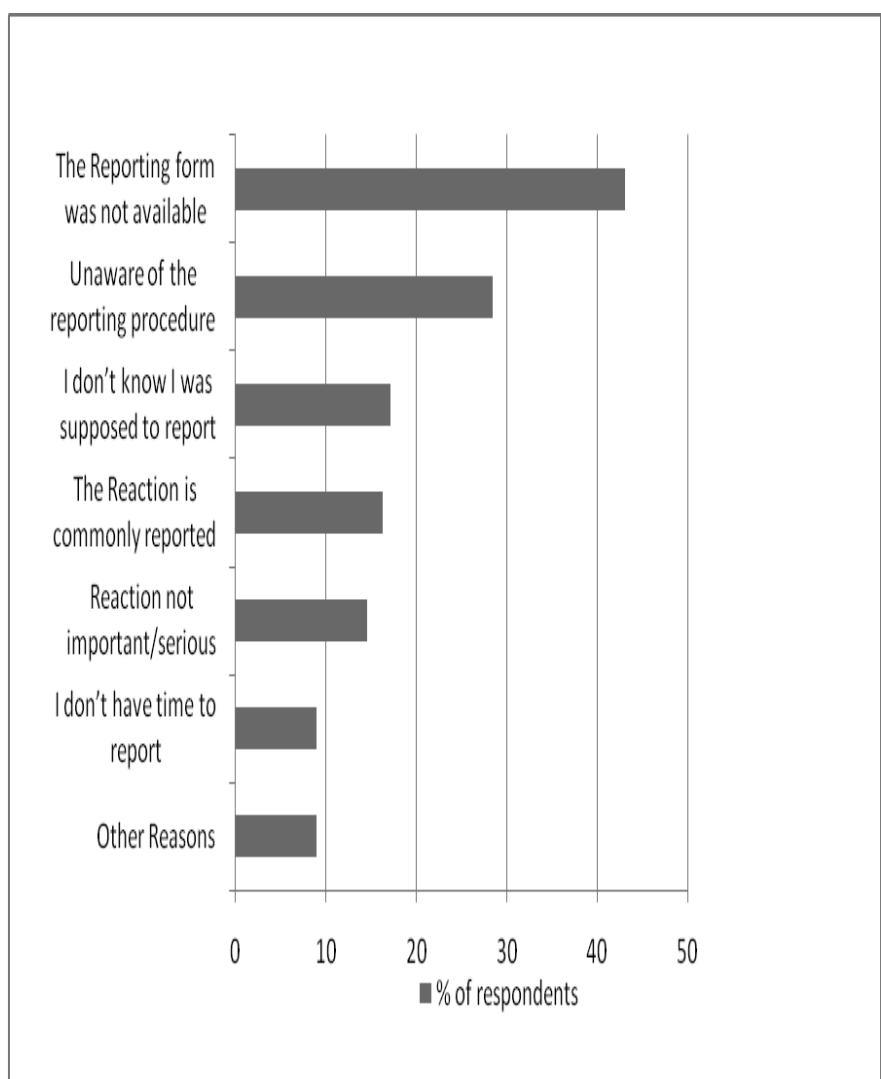

Figure 1 Reasons for not reporting an adverse event seen by a doctor

Training, type of health facility, doctors' rank and level of knowledge of ADR reporting were found to be associated with the likelihood of reporting and ADR (Table $3)$.

Two hundred and twenty-five (96.4\%) of the doctors agreed that it was their professional responsibility to report ADRs, and further indicated that other healthcare professionals should also report same. 
One hundred and sixty (70.0\%), $146(61.1 \%)$ and 141 $(59.0 \%)$ of doctors suggested that pharmacists, nurses and medical assistants respectively should report suspected ADRs as this will help improve the reporting rates.

Table 3 Odds of ADR Reporting by Doctors.

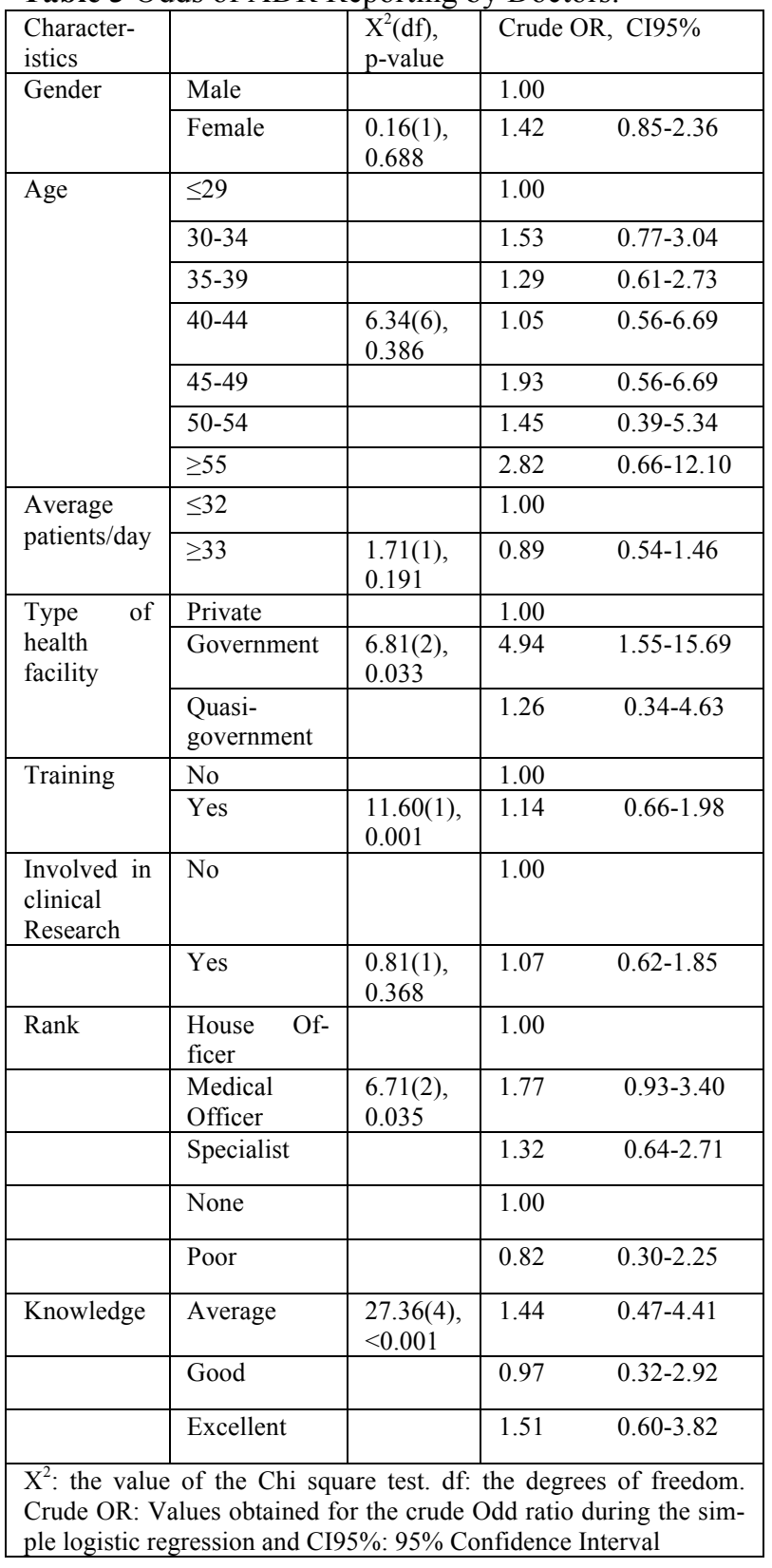

\section{DISCUSSION}

Most of the doctors surveyed were young ( $<40$ years of age). There were significantly more males than females, in concordance with the general distribution of sexes in Ghanaian medical schools. About half of the doctors were medical officers, who by definition are general practitioners, the remaining half comprised specialists and house officers (Table 1).

Less than one-third (27.4\%) of the doctors who participated in this study acknowledged receiving prior training on drug safety monitoring and ADR reporting. Of the various types of health facility, government and quasi-government had the largest proportions of doctors trained in ADR reporting compared the not-trained (Table 2). This is not surprising since training and sensitization on pharmacovigilance organized by Ghana's National Pharmacovigilance Centre has taken place mostly in government and quasi-government hospitals. ${ }^{17}$ Of doctors reporting adverse drug reactions, over $58 \%$ had been trained. Training was found to significantly improve ADR reporting (p-value $<0.001$ ) (Table 3 ) in accordance with other studies. ${ }^{12,13}$

The general impression is that training can help improve reporting. However, it is well known that ADR reporting is affected by many other factors other than training. In this study the type of health facility was found to have an influence on the likelihood of reporting an ADR. Doctors in government facilities had the highest reporting rate. While doctors in government facilities were almost 5 times more likely to report an ADR compared to those in private facilities, doctors in quasi-government hospitals were 1.26 times more likely to report an ADR compared to doctors in private facilities (Table 3 ).

Medical officers and specialists were significantly more likely to report an ADR compared to house officers (Table 3). This could be due to the fact that training programmes organized by the National Pharmacovigilance Centre in the years preceding this study excluded house officers because they were in medical school at the time. To improve the ADR reporting rate among house officers, the National Pharmacovigilance Centre needs to liaise with the medical schools to introduce training on spontaneous reporting to students prior to graduation. Interestingly the average number of patients seen in a day and involvement in clinical research by doctors was not found to be associated with the likelihood of reporting an ADR (Table 3).

Although more than half $(59.5 \%)$ of the doctors interviewed had seen at least one patient with an ADR in the preceding year, less than a quarter $(20 \%)$ of those who saw a patient with a reaction went further to complete the spontaneous ADR reporting form. Almost all the doctors $(96.4 \%)$ on the other hand, agreed that it was their professional responsibility to report ADRs. 
Why this did not translate into physical reports is attributable to a number of factors such as unavailability of reporting forms in consulting rooms, commonness of the reactions, the fact that the reactions were not serious, lack of knowledge of the reporting system/procedure, lack of understanding of the need to report, and lack of time to fill the form probably due to heavy a workload.

They went further to suggest that other health professionals should participate actively in reporting ADRs, and receiving feedback on actions taken regarding their reports will encourage them to report more frequently. These reasons need serious consideration by the country's pharmacovigilance officials and should be approached in a holistic fashion in order to help improve reporting rates among doctors and other health professionals.

\section{CONCLUSION}

Training was found to be significantly associated with improved ADR reporting. Most of the doctors who participated in this study had not previously received training on ADR reporting. Reporting forms should be made readily available to the doctors, training and refresher courses should be organized, and each report submitted by a doctor should be acknowledged and prompt feedback given on the actions taken.

\section{REFERENCES}

1. Alvarez-Requejo A, Carvajal A, Begaud B, et al. Under-reporting of adverse drug reactions. Estimate based on a spontaneous reporting scheme and a sentinel system. Eur. J. Clin. Pharmacol. 1998;54(6):483-8. Epub 1998/10/17.

2. Pal S, Dodoo A, Mantel A, et al. The world medicines situation 2011: Pharmacovigilance and safety of medicines. Geneva: WHO, 2011 [cited 2012 Apr 5]. Available from:

http://apps.who.int/medicinedocs/documents/s187 71en/s18771en.pdf

3. Dodoo A. Pharmacovigilance in West Africa. Uppsala Reports. 2002;19:8-9.

4. WHO. Reporting Trends. [cited 2012 Jun 6]. Available from: http://whoumc.org/DynPage.aspx?id=108476\&mn1=7347\& $\mathrm{mn} 2=7252 \& \mathrm{mn} 3=7322 \& \mathrm{mn} 4=7558$.

5. Belton KJ. Attitude survey of adverse drugreaction reporting by health care professionals across the European Union. The European Pharmacovigilance Research Group. Eur. J. Clin. Pharmacol. 1997;52(6):423-7. Epub 1997/01/01.
6. Aagaard L, Stenver DI, Hansen EH. Structures and processes in spontaneous ADR reporting systems: a comparative study of Australia and Denmark. Pharm. World Sci. 2008;30(5):563-70. Epub 2008/03/20.

7. Bello SO, Umar MT. Knowledge and attitudes of physicians relating to reporting of adverse drug reactions in Sokoto, north-western Nigeria. Ann Afri. Med. 2011;10(1):13-8. Epub 2011/02/12.

8. Oshikoya KA, Awobusuyi JO. Perceptions of doctors to adverse drug reaction reporting in a teaching hospital in Lagos, Nigeria. BMC Clin Pharmacol. 2009;9:14. Epub 2009/08/13.

9. Enwere OO, Fawole OI. Adverse drug reactions reporting by physicians in Ibadan, Nigeria. Pharmacoepidemiology and Drug Saf. 2008;17:517-22.

10. Inman WH. Attitudes to adverse drug reaction reporting. Br J. Clin Pharmacol. 1996;41(5):4345. Epub 1996/05/01.

11. Lopez-Gonzalez L. Determinants of UnderReporting of Adverse Drug Reactions: A Systematic Review. Drug Saf. 2009;32(1):19-31.

12. Green CF, Mottram DR, Rowe PH, et al. Attitudes and knowledge of hospital pharmacists to adverse drug reaction reporting. $\mathrm{Br} \mathrm{J}$. Clin Pharmacol. 2001;51(1):81-6. Epub 2001/02/13.

13. Figueiras A, Herdeiro MT, Polonia J, et al. An educational intervention to improve physician reporting of adverse drug reactions: a clusterrandomized controlled trial. JAMA. 2006;296(9):1086-93. Epub 2006/09/07.

14. Ghana Medical and Dental Council. List of medical and dental practitioners registered in Ghana for 2011 [cited 2012 Jun 6]. Available from: http://www.mdcghana.org/pdfs/STANDING\%20R EGISTER\%202011.pdf.

15. Ghana Statistical Service. Population and Housing Census, Population by Region and Sex, 2010 [cited 2012 Sep 20]. Available from: http://www.statsghana.gov.gh/docfiles/2010phc/20 10 population_and housing_census $\% 28$ view_pop ulation_by_sex_regional_and_district\%29.pdf.

16. Ministry of Health. Independent review of the health sector programme of work 2008 [cited 2012 Sep 12]. Available from: http://www.mohghna.org/UploadFiles/Publications/ANNUALREV IEWREPORT2008090825071054.pdf.

17. Food and Drugs Authority. Annual Report for the National Pharmacovigilance Centre. Food and Drugs Authority, Ghana, 2010 [cited 2012 Nov 10]. Available from: http://fdaghana.gov.gh/images/stories/pdfs/Annual \%20Reports/Annual\%20Report\%202010.pdf $\bullet$ 